\title{
A PROSPECTIVE STUDY OF CHOLECYSTECTOMY IN A SINGLE SURGICAL UNIT
}

\author{
Wormi Sharon ${ }^{1}$, NG. Javan ${ }^{2}$
}

${ }^{1}$ Senior Resident, Department of Surgery, Jawaharlal Institute of Medical Sciences, Porompat, Imphal, Manipur. ${ }^{2}$ Assistant Professor, Department of Surgery, Jawaharlal Institute of Medical Sciences, Porompat, Imphal, Manipur.

\begin{abstract}
\section{BACKGROUND}

As the number of surgeons performing laparoscopic cholecystectomy, a rigorous evaluation of the safety of laparoscopic cholecystectomy is warranted. It is essential to determine the extent of the difference in morbidity and mortality when compared with open cholecystectomy. Laparoscopic cholecystectomy is now the Gold standard treatment for gallstone disease. All these inventions are invented by trial and error basis, so complete study is needed to know the pros and cons of these new techniques. This study is one such effort.
\end{abstract}

\section{MATERIAL AND METHODS}

The study was conducted over a period of 12 months from 1stJanuary 2015 to $31^{\text {st }}$ December 2015.Allthepatientswhounderwent laparoscopic operation for symptomatic gallstone disease during this period were taken as subjects for study. A total of 111 cholecystectomies were performed by one surgical team over a 12-month period.

\section{RESULT}

Out of the 111 patients undergoing cholecystectomy, 93 (83.8\%) were female and remaining $18(16.2 \%)$ male. In 66 patients undergoing Laparoscopic cholecystectomy, 57 (86.36\%) got discharged from the hospital within 72 hours compared to 45 patients undergoing open cholecystectomy, only 19 (42.22\%) got discharged within 72 hours.

\section{CONCLUSION}

Laparoscopic cholecystectomy is essentially a safe procedure with low morbidity and mortality rate. Patients undergoing Laparoscopic cholecystectomy return to their normal activities much earlier compared to those patients undergoing open cholecystectomy.

\section{KEYWORDS}

Cholelithiasis; Laparoscopic Cholecystectomy; Open Cholecystectomy.

HOW TO CITE THIS ARTICLE: Sharon W, Javan NG. A prospective study of cholecystectomy in a single surgical unit. J. Evolution Med. Dent. Sci. 2016;5(71):5169-5172, DOI: 10.14260/jemds/2016/1172

\section{INTRODUCTION}

Open cholecystectomy has been the gold standard of treatment for cholelithiasis for more than 100 years. Laparoscopic cholecystectomy has revolutionised our approach to a number of problems and caused a re-evaluation of clinical strategies. Now, it has become the standard therapy for symptomatic gallstone disease particularly in elective setting. The advantages of laparoscopic cholecystectomy over traditional open cholecystectomy in terms of limited postoperative pain, shorter hospitalisation, early resumption of activity and improved cosmetic have been readily apparent. Over the past 2 years, there has been an enormous increase in the popularity of the new operative technique of laparoscopic cholecystectomy. Cholecystectomy is the most common major general surgical operation. Despite the large number of publications on the subject, the majority of papers lack no scientific comparisons with the open operations, but make presumptive claims of the benefits of the laparoscopic approach. In the few articles that do give comparative data, the information has been collected retrospectively and no attempt has been made to randomise.(1)

Financial or Other, Competing Interest: None.

Submission 26-07-2016, Peer Review 19-08-2016,

Acceptance 26-08-2016, Published 03-09-2016.

Corresponding Author:

Dr. Wormi Sharon,

Grace Colony, Opposite Grace Academy,

Tarung, Imphal-795004,

Manipur.

E-mail:dr.wormisharon@gmail.com

DOI: $10.14260 /$ jemds $/ 2016 / 1172$
In September 1992, a National Institute of Health (NIH) consensus conference held in Bethesda concluded that laparoscopic cholecystectomy was treatment of choice for gallbladder stones: it is now become the gold standard treatment for gallbladder-related disease.(2) One study set out to perform a randomised controlled trial, but have to abandon the attempt because of ethical constraints.(3) They concluded that the only way to assess the new technique was to use 'comprehensive surveillance.'

Theaim of thisstudy, therefore, was to evaluate in a large heterogeneous population the outcome of laparoscopic cholecystectomy and its comparison with open cholecystectomy in terms of outcome and complication rate in single surgical unit of our institution.

\section{PATIENTS AND METHODS}

The study was conducted over a period of 12 months from 1st January 2015 to $31^{\text {st }}$ December 2015. All the patients who underwent laparoscopic operation for symptomatic gallstone disease during this period were taken as subjects for study. A total of 111 cholecystectomies were performed by one surgical team over a 12-month period.

The open cholecystectomy was performed through a 10$12 \mathrm{~cm}$ right subcostal incision, which involved cutting the rectus muscle to give access to the peritoneal cavity. In the laparoscopic approach, we insufflated the peritoneum through a Veress needle placed above the umbilicus and then introduced a $10-\mathrm{mm}$ trocar to allow insertion of a telescope carrying a video camera. We then placed instruments through 
three further points, one under the xiphisternum, one under the costal margin in the midclavicular line and another on the anterior axillary line. Positions varied depending on the size and shape of the patient and on the relative position of the gallbladder. The operative technique was very much the same for each procedure. The anatomy of Calot's triangle was clearly identified. The cystic duct and artery isolated separately, clipped and divided and the gallbladder was then dissected from the liver with diathermy and removed via the $10-\mathrm{mm}$ port under the xiphisternum.

The factors recorded during the study were recovery, pain perceived and complications. Recovery was measured by recording the duration of intravenous fluids, the time to oral fluids and diet and the number of days to discharge home. Postoperative pain was assessed by measuring the duration of intramuscular narcotic analgesia. The laparoscopic technique gave excellent exposure, which was often superior to that achieved in open surgery particularly in the obese patient. Blood loss during laparoscopic surgery was minimal with no patient requiring transfusion.

\section{RESULTS}

Out of the 111 patients undergoing cholecystectomy, 93 $(83.8 \%)$ were female and remaining $18(16.2 \%)$ male. The sex distribution and the age distribution as shown in table 1 and 2 .

\begin{tabular}{|c|c|c|}
\hline & Total No. of Patients & Percentage \\
\hline Male & 18 & 16.2 \\
\hline Female & 93 & 83.8 \\
\hline Total & $\mathbf{1 1 1}$ & $\mathbf{1 0 0}$ \\
\hline \multicolumn{2}{|c|}{ Table 1: Sex Distribution } \\
\hline
\end{tabular}

\section{Sex Distribution}

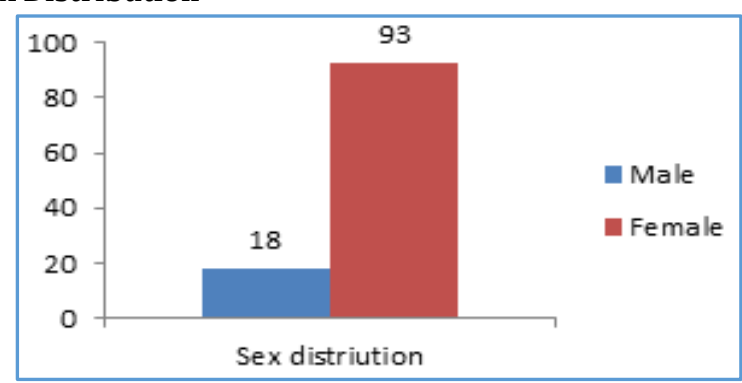

\begin{tabular}{|c|c|c|}
\hline Years & Frequency & Percentage \\
\hline $1-20$ & 9 & 8.1 \\
\hline $21-40$ & 56 & 50.5 \\
\hline $41-60$ & 33 & 29.7 \\
\hline$>60$ & 13 & 11.7 \\
\hline Total & $\mathbf{1 1 1}$ & $\mathbf{1 0 0}$ \\
\hline \multicolumn{3}{|c|}{ Table 2: Age Distribution } \\
\hline
\end{tabular}

\section{Age Distribution}

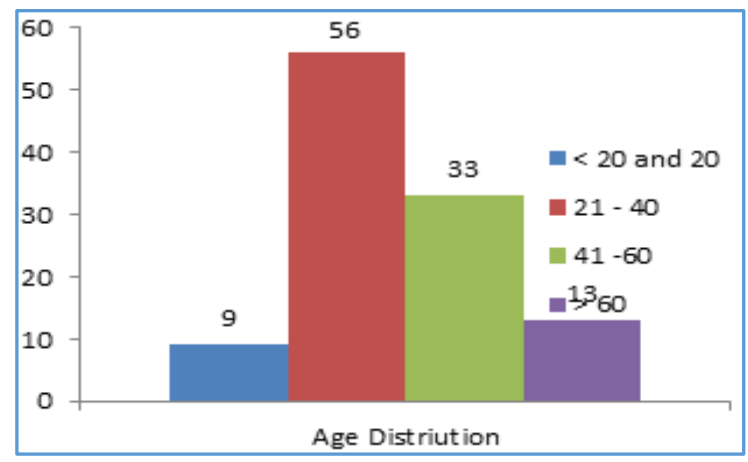

Out of 111 patients undergoing cholecystectomy, 66 patients underwent laparoscopic cholecystectomy and the remaining underwent open cholecystectomy. The type of surgery is mainly decided by patient's choice and other medical factors.

\begin{tabular}{|c|c|c|}
\hline & Frequency & Percentage \\
\hline Open & 45 & 38.7 \\
\hline Laparoscopic & 66 & 59.5 \\
\hline Total & $\mathbf{1 1 1}$ & $\mathbf{1 0 0}$ \\
\hline \multicolumn{2}{|c|}{ Table 3: Type of Surgery Performed } \\
\hline
\end{tabular}

\section{Type of Surgery}

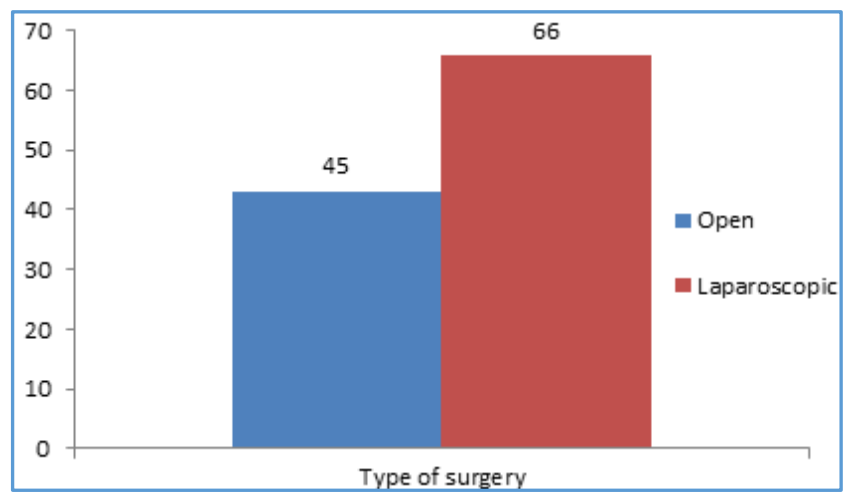

In all the 66 laparoscopic cholecystectomies only 1 was converted to open cholecystectomy in view of abnormal anatomy and not able to define the Calot's triangle. The recovery of this patient was uneventful. The laparoscopic technique gave excellent exposure, which was often superior to that achieved in open surgery particularly in the obese patient. Blood loss during laparoscopic surgery was minimal with no patient requiring transfusion.

Patients who had laparoscopic cholecystectomy started oral fluids and diet earlier than after open cholecystectomy. Discharge home was most dramatically improved by laparoscopy. This is shown in table 5 and 6 . Objective measurement of pain showed that patients required significantly less narcotic analgesia after laparoscopy than after open cholecystectomy. Postoperatively, measurement of pain perceived was significantly less after laparoscopic cholecystectomy compared with the open approach.

The complications are listed in Table 4. In the open group, there were four patients who had exploration of the common bile duct; exploration was not performed in any of the laparoscopic patients. There was one duct injury in the open group, repaired successfully, and none in the laparoscopic group. There were 10 cases of wound infection in open cholecystectomy group and none in laparoscopic cholecystectomy.

\begin{tabular}{|c|c|c|}
\hline Complications & Open $(\mathbf{n = 4 5 )}$ & $\begin{array}{c}\text { Laparoscopic } \\
(\mathbf{n}=\mathbf{6 6})\end{array}$ \\
\hline CBD exploration & 4 & 0 \\
\hline Duct injury & 1 & 0 \\
\hline Wound infection & 10 & 0 \\
\hline Conversion to open & 1 \\
\hline \multicolumn{2}{|c|}{ Table 4: Complications } \\
\hline
\end{tabular}

\begin{tabular}{|c|c|c|}
\hline Days & Frequency & Percentage \\
\hline$<3$ & 19 & 42.22 \\
\hline$>3$ & 26 & 57.77 \\
\hline Total & $\mathbf{4 5}$ & $\mathbf{1 0 0}$ \\
\hline \multicolumn{2}{|c|}{ Table 5: Days in Hospital (Open Cholecystectomy) } \\
\hline
\end{tabular}




\begin{tabular}{|c|c|c|}
\hline Days & Frequency & Percentage \\
\hline$<3$ & 57 & 86.36 \\
\hline$>3$ & 9 & 13.63 \\
\hline Total & $\mathbf{6 6}$ & $\mathbf{1 0 0}$ \\
\hline \multicolumn{2}{|c|}{ Table 6: Days in Hospital (Laparoscopic } \\
Cholecystectomy)
\end{tabular}

\section{DISCUSSION}

Open cholecystectomy has been the gold standard of treatment for cholelithiasis for more than 100 years with the mortality rate that have declined to $0-1 \%$ in most recent reports and the rate of major complications of approximately $4.5 \%$. The introduction of a new therapy into modern medical practice requires careful assessment in order to ensure its safety and efficacy. There are strict regulations set by law for a new drug. This is not the case for new techniques in surgery, but it behoves the surgical community to monitor their own endeavours. The introduction of laparoscopic surgery especially in cholecystectomy where it is being applied so enthusiastically is a vitally important area for surgeons to assess carefully.

Jatzko and others( 4 in their study reported mortality rate of $0 \%$ and $0.2 \%$ in open and laparoscopic cholecystectomy group respectively. Few attempts have been made to carry out prospective randomised trials of the laparoscopic and open approach to cholecystectomy and no such study has been completed. The authors of the attempt that failed described problems with randomisation when patients or their surgeons perceived a great benefit from the new procedure and it was felt unethical to place patients in the control arm.(5) In fact, randomised trials are not impossible in surgical practice as we have recently successfully completed a fully randomised prospective trial of laparoscopic versus open appendicectomy,(1) but during the latter study laparoscopic appendicectomy had not gained popular acclaim with either patients or surgeons in contrast to the almost universal application of laparoscopy to cholecystectomy that has taken place in our region. Our study of the technique of cholecystectomy has attempted to make a valid comparison between the new laparoscopic approach and the traditional open laparotomy procedure used since its introduction in 1888.

This study performed over a 12-month period compares both techniques and has not used data collected retrospectively. Also, because the procedures were performed by one surgical team, this lessened the chance of interoperator bias. Indeed, since the laparoscopic technique was only being introduced, any advantage reported is likely to be underestimated. This study has been able to show that laparoscopic cholecystectomy allows faster patient recovery, earlier full mobilisation and discharge home than after open cholecystectomy. The speed of recovery is similar to that reported by other European studies for laparoscopic surgery, ${ }^{(6-7)}$ but in our study recovery has been compared prospectively with the open operation. We have not studied return to work, but note that on return to the outpatients department at 5-7 days after surgery, most patients were leading an active life. The advantage of this rapid recovery is the single most attractive feature of the laparoscopic technique both from the patient's viewpoint and for hospital cost-effectiveness. In the study conducted by Kani et al,(8) mean hospital stay was 1.6 days in LC and it was 4.3 days in OC Barkun JS.(9)
Reported mean hospital stay of $2 \pm 2$ days in LC and $6 \pm 4$ days in OC. Wound infection was more in patients undergoing open cholecystectomy compared to those laparoscopic cholecystectomy. Jatzko et al(9) in their study observed that wound infection rate is lower in LC group $(0.3 \%)$ as compared to OC group (5.1\%). Barkun JS et al(5) in Toronto group study also observed that LC complications were significantly less than OC complication. Siddiqui etal(10) in their study observed that frequency of wound infection was three times $(6 \%)$ common in OC as compared to LC (2\%) in acute cholecystitis.

Iqbal et al(11) in their study observed that morbidity due to pain, fever, nausea and vomiting, respiratory and wound complicationswere significantly lessin LCgroup as compared to OC group. Mean duration for tolerating oral feeding and postoperative hospital stay were found to be shorter in LC group than in OC group.

Barken JS(12) in Toronto study reported a mean duration of return to normal work as $6 \pm 3$ weeks in OC group and $1 \pm 2$ weeks in LC group. Kane et al reported mean duration of 28 days in OC group and 10 days in laparoscopic cholecystectomy group $(\mathrm{p}<0.001)$.

Keus et al(10) in their study found no significant difference in mortality, complications and operative time. However, the laparoscopic cholecystectomy was associated with the shorter hospital stay and quicker recovery as compared to open cholecystectomy.

There is concern about the possibility of an increased incidence of bile duct injury with laparoscopic cholecystectomy. Our study is too small to provide any conclusive evidence on safety. A series of 1000 cases would need to be studied in order to compare with the previous incidence of 1 in 300-500 for open cholecystectomy estimated by Baer and Blumgart for populations in Europe and Australia.(13)

Mufti etal(8) also found LC to be safe and effective treatment for gallstone disease. Cawich et al(10) found that minor complications to be common after OC (11\%) v s. LC (4\%).

Contrary to initial reports of an increased complication rate, recent data show that LC entails lower morbidity and mortality rates than open operation.(14-17) Laparoscopic cholecystectomy has clearly displaced open cholecystectomy in the management of simple biliary lithiasis.(18-20)

Laparoscopic cholecystectomy is more cost-effective than open cholecystectomy. However, in a system of free health care, the effect of the new technology does not directly reduce the resources used by the hospital. In fact, because the efficiency is so much improved it allows the hospital to treat more patients and the end result is an increase in the total resource used while the cost per patient is reduced. The biggest impact of the new technology is that it has allowed many patients to have their operation who would otherwise have stayed on a long waiting list. Laparoscopic cholecystectomy is feasible in more than $90 \%$ of patients and compared with the open operation is safe with less preoperative and postoperative morbidity and associated with faster patient recovery because of less postoperative pain, earlier return to diet and earlier full mobilisation and discharge home. Guidelines for prevention of operative injury are similar to those of any operative procedure namely adequate training and experience, proper execution of appropriate technique and accurate identification of the 
anatomy. We would suggest that this study indicates that laparoscopic cholecystectomy is superior to open cholecystectomy and should therefore be available to all patients requiring elective cholecystectomy.

\section{REFERENCES}

1. Neugebauer E, Troidl $H$, Spangenberger $W$, et al Conventional versus laparoscopic cholecystectomy and the randomized controlled trial. Cholecystectomy Study Group. Br J Surg 1991;78(2):150-4.

2. Nathanson LK, Shimi S, Cuschieri A. Laparoscopic cholecystectomy: the Dundee technique. $\mathrm{Br}$ J Surg 1991;78(2):155-9.

3. Jani K, Rajan PS, Palanivelu C, et al. Twenty years after Erich Muhe: Persisting controversies with the gold standard of laparoscopic cholecystectomy. J Minim Access Surg. 2006;2(2):49-58.

4. Reddick EJ, Olsen D, Spaw A, et al. Safe performance of difficult laparoscopic cholecystectomies. Am J Surg. 1991;161(3):377-81.

5. Jatzko GR, Lisborg PH, Pertl AM, et al. Multivariate comparison of complications after laparoscopic cholecystectomy and open cholecystectomy. Ann Surg. 1995;221(4):381-6.

6. Attwood SE, Hill AD, Murphy PG, et al. A prospective randomized trial of laparoscopic versus open appendectomy. Surgery 1992;112(3):497-501.

7. Olsen DO. Laparoscopic cholecystectomy. Am J Surg. 1991;161(3):339-44.

8. Grace PA, Quereshi A, Coleman J, et al. Reduced postoperative hospitalization after laparoscopic cholecystectomy. Br J Surg. 1991;78(2):160-2.

9. Kane RL, Lurie N, Borbas C, et al. The outcomes of elective laparoscopic and open cholecystectomies. J Am Coll Surg. 1995;180(2):136-45.

10. Barkun JS, Barkun AN, Meakins JL. Laparoscopic versus open cholecystectomy: the Canadian experience. The McGill Gallstone Treatment Group. Am J Surg. 1993;165(4):455-8.
11. Siddiqui K, Khan AF. Comparison of frequency of wound infection: open vs laparoscopic cholecystectomy. J Ayub Med Coll Abbottabad 2006;18(3):21-4.

12. Iqbal J, Ahmed B, Iqbal $Q$, et al. Laparoscopic V/S open cholecystectomy morbidity comparison. Professional Med J 2002;9(3):226-35.

13. Keus F, de Jong JA, Gooszen HG, et al. Laparoscopic versus open cholecystectomy for patients with symptomatic cholecystolithiasis. Cochrane Database Syst Rev. 2006;18(4):CD006231.

14. Deziel DJ, Millikan KW, Economou SG, et al. Complications of laparoscopic cholecystectomy: a national survey of 4,292 hospitals and an analysis of 77,604 cases. Am J Surg 1993;165(1):9-14.

15. Bailey RW, Zucker KA, Flowers JL, et al. Laparoscopic cholecystectomy. Experience with 375 consecutive patients. Ann Surg. 1991;214(4):531-41.

16. Febre JM, Fagot H, Domergne J, et al. Laparoscopic cholecystectomy in complicated cholelithiasis. Surg Endosc 1994;8(10):1198-201.

17. Huang SM, Wu CW, Hong HT, et al. Bile duct injury and bile leakage in laparoscopic cholecystectomy. Br J Surg. 1993;80(12):1590-2.

18. Cuschieri A, Dubois F, Mouiel J, et al. The European experience with laparoscopic cholecystectomy. Am J Surg. 1991;161(3):385-7.

19. Dubois F, Berthelot G, Levard H. Laparoscopic cholecystectomy: historic perspective and personal experience. Surg Laparosc Endosc 1991;1(1):52-7.

20. Spaw AT, Reddick EJ, Olsen DO. Laparoscopic laser cholecystectomy: analysis of 500 procedures. Surg Laparosc Endosc 1991;1(1):2-7. 